\title{
Rapid and Effective Virucidal Activity of Povidone- Iodine Products Against Middle East Respiratory Syndrome Coronavirus (MERS-CoV) and Modified Vaccinia Virus Ankara (MVA)
}

\author{
Maren Eggers · Markus Eickmann · Juergen Zorn
}

To view enhanced content go to www.infectiousdiseases-open.com Received: September 7, 2015 / Published online: September 28, 2015

(C) The Author(s) 2015. This article is published with open access at Springerlink.com

\section{ABSTRACT}

Introduction: Since the first case of Middle East Respiratory Syndrome coronavirus (MERS-CoV) infection was reported in 2012, the virus has infected more than 1300 individuals in 26 countries, and caused more than 480 deaths. Human-to-human transmission requires close contact, and has typically occurred in the healthcare setting. Improved global awareness, together with improved hygiene practices in healthcare facilities, has been highlighted as key strategies in controlling the spread of MERS-CoV. This study tested the in vitro efficacy of three formulations of povidone

Electronic supplementary material The online version of this article (doi:10.1007/s40121-015-0091-9) contains supplementary material, which is available to authorized users.

\section{Eggers}

Labor Prof. Gisela Enders MVZ GbR and the Institute of Virology, Infectious Diseases and Epidemiology e.V., Stuttgart, Germany

\section{Eickmann}

Institute for Virology, Philipps University of

Marburg, Marburg, Germany

\section{J. Zorn (ه)}

Mundipharma Research GmbH \& Co.KG, Limburg, Germany

e-mail: Juergen.zorn@mundipharma-rd.eu iodine (PVP-I: 4\% PVP-I skin cleanser, 7.5\% PVP-I surgical scrub, and $1 \%$ PVP-I gargle/mouthwash) against a reference virus (Modified vaccinia virus Ankara, MVA) and MERS-CoV.

Methods: According to EN14476, a standard suspension test was used to assess virucidal activity against MVA and large volume plating was used for MERS-CoV. All products were tested under clean $(0.3 \mathrm{~g} / \mathrm{L}$ bovine serum albumin, BSA) and dirty conditions $(3.0 \mathrm{~g} / \mathrm{L}$ $\mathrm{BSA}+3.0 \mathrm{~mL} / \mathrm{L}$ erythrocytes), with application times of 15, 30, and $60 \mathrm{~s}$ for MVA, and $15 \mathrm{~s}$ for MERS-CoV. The products were tested undiluted, 1:10 and 1:100 diluted against MVA, and undiluted against MERS-CoV.

Results: A reduction in virus titer of $\geq 4 \log _{10}$ (corresponding to an inactivation of $\geq 99.99 \%$ ) was regarded as evidence of virucidal activity. This was achieved versus MVA and MERS-CoV, under both clean and dirty conditions, within $15 \mathrm{~s}$ of application of each undiluted PVP-I product.

Conclusion: These data indicate that PVP-I-based hand wash products for potentially contaminated skin, and PVP-I gargle/mouthwash for reduction of viral load 
in the oral cavity and the oropharynx, may help to support hygiene measures to prevent transmission of MERS-CoV.

Funding: Mundipharma Research GmbH \& Co.

Keywords: Enveloped virus; Gargle; Hand hygiene; MERS-CoV; Middle East respiratory syndrome coronavirus; Modified vaccinia virus Ankara; Mouthwash; MVA; Povidone iodine; Virucidal

\section{INTRODUCTION}

Four of the six coronaviruses (CoVs) that have made the transition from mammalian/avian hosts to humans are endemic in the human population, and typically associated with mild, self-limiting respiratory illness [1]. However, the remaining two human CoVs cause severe respiratory syndromes and are associated with considerable mortality [1]. In 2003, the severe acute respiratory syndrome (SARS)-CoV caused a disease outbreak that claimed nearly 800 lives [2], and for the second consecutive decade this century, a new human CoV has emerged. The Middle East Respiratory Syndrome (MERS)-CoV was first isolated from a 60-year-old man in Saudi Arabia in June 2012 [3]. Three years later, it has been responsible for the infection of more than 1300 individuals in 26 countries, and more than 480 related deaths [4].

Of all the cases of MERS-CoV reported to date, three quarters have occurred within the source country of Saudi Arabia (Table 1) [4]. Aside from a moderate outbreak in the United Arab Emirates (UAE), travel-associated spread to other countries in the Middle East, as well as examples in Europe, North America, Africa and Asia, has typically resulted in very minimal local outbreaks. The clear exception to this is situation in the Republic of Korea, where over
180 cases have been reported, all during 2015 [4]. Infection in the index case followed recent travel to Saudi Arabia, Qatar, UAE and Bahrain [5]. An International Health Regulations Emergency Committee has highlighted five main factors contributing to the spread of MERS-CoV in the Republic of Korea [6]. Briefly, these were (1) a lack of awareness among healthcare workers and the general public; (2) suboptimal infection prevention and control measures in hospitals; (3) crowded emergency rooms and multi-bed hospital rooms; (4) the practice of patients seeking care at multiple hospitals; (5) multiple visitors staying with infected patients in hospital rooms.

Overall, clinical experience with MERS-CoV indicates that its spread within the human population requires close contact; the majority of cases have resulted from human-to-human transmission in healthcare settings [7]. There is good potential for outbreaks to be contained, given suitable levels of awareness and hygiene. The latest outbreak in Korea, however, is testament to the cost of neglecting these basic requirements. A recent study by our group demonstrated impressive, rapid virucidal activity of povidone iodine (PVP-I) against the Ebola virus (EBOV) [8]. PVP-I was also effective against the European reference virus (Modified vaccinia virus Ankara; MVA), which was determined to be a suitable surrogate test agent, facilitating the safe testing of the virucidal activity of antiseptic products against hazardous pathogens, including enveloped viruses such as EBOV [8]. PVP-I is a broad-spectrum antimicrobial, used globally in the medical field-including the Middle Eastas a disinfectant for skin, hands and mucosal surfaces as well as for wound treatment and eye applications [9]. 
Table 1 Number of laboratory-confirmed cases of MERS-CoV reported to WHO, by country and year

\begin{tabular}{|c|c|c|c|c|c|}
\hline Country & 2012 & 2013 & 2014 & 2015 & Total \\
\hline \multicolumn{6}{|l|}{ Middle East } \\
\hline Saudi Arabia & 5 & 136 & 679 & 217 & 1037 \\
\hline United Arab Emirates & 0 & 12 & 57 & 7 & 76 \\
\hline Qatar & 0 & 7 & 2 & 4 & 13 \\
\hline Jordan & 2 & 0 & 10 & 0 & 12 \\
\hline Oman & 0 & 1 & 1 & 4 & 6 \\
\hline Iran & 0 & 0 & 5 & 1 & 6 \\
\hline Kuwait & 0 & 2 & 1 & 0 & 3 \\
\hline Yemen & 0 & 0 & 1 & 0 & 1 \\
\hline Total & 7 & 158 & 756 & 233 & 1154 \\
\hline \multicolumn{6}{|l|}{ Southeast Asia } \\
\hline Republic of Korea & 0 & 0 & 0 & 185 & 185 \\
\hline Philippines & 0 & 0 & 0 & 2 & 2 \\
\hline China & 0 & 0 & 0 & 1 & 1 \\
\hline Thailand & 0 & 0 & 0 & 1 & 1 \\
\hline Malaysia & 0 & 0 & 1 & 0 & 1 \\
\hline Total & 0 & 0 & 1 & 189 & 190 \\
\hline
\end{tabular}

Europe

United Kingdom
Germany
The Netherlands
France
Austria
Greece
Italy
Total

$\begin{array}{ll}1 & 3 \\ 1 & 1 \\ 0 & 0 \\ 0 & 2 \\ 0 & 0 \\ 0 & 0 \\ 0 & 1 \\ 2 & 7\end{array}$

$\begin{array}{lll}0 & 0 & 4 \\ 0 & 1 & 3 \\ 2 & 0 & 2 \\ 0 & 0 & 2 \\ 1 & 0 & 1 \\ 1 & 0 & 1 \\ 0 & 0 & 1 \\ 4 & 1 & 14\end{array}$

Mediterranean and Arab countries

\begin{tabular}{llllll} 
Tunisia & 0 & 3 & 0 & 0 & 3 \\
Algeria & 0 & 0 & 2 & 0 & 2 \\
Egypt & 0 & 0 & 1 & 0 & 1 \\
Lebanon & 0 & 0 & 1 & 0 & 1 \\
Turkey & 0 & 0 & 1 & 0 & 1 \\
Total & 0 & 3 & 5 & 0 & 8 \\
\hline
\end{tabular}


Table 1 continued

\begin{tabular}{llccrr}
\hline Country & $\mathbf{2 0 1 2}$ & $\mathbf{2 0 1 3}$ & $\mathbf{2 0 1 4}$ & $\mathbf{2 0 1 5}$ & Total \\
\hline North America & & & & & \\
United States of America & 0 & 0 & 2 & 0 & 2 \\
Total & 0 & 0 & 2 & 0 & 1368 \\
Total & 9 & 168 & 768 & 423 & 2 \\
\hline
\end{tabular}

Data as of 7 July 2015 [4]

MERS-CoV Middle East respiratory syndrome coronavirus, WHO World Health Organization

It may be hypothesized that PVP-I would also demonstrate effective disinfectant properties against MERS-CoV. The study reported here evaluated skin cleanser, surgical scrub and gargle/mouthwash formulations of PVP-I for virucidal activity against both the reference virus MVA and MERS-CoV itself.

\section{METHODS}

\section{Virucidal Products Tested}

Three PVP-I antiseptic products were tested in this study: 4\% PVP-I skin cleanser, 7.5\% PVP-I surgical scrub and 1\% PVP-I gargle/mouthwash, each with the brand name Betadine, manufactured by Mundipharma (Limburg, Germany). This article does not contain any new studies with human or animal subjects performed by any of the authors.

\section{Propagation of the Test Virus}

\section{MVA}

Methodology for propagation of MVA was as described in [8]. Briefly, baby hamster kidney cells (BHK)-21 cells (cell bank of Friedrich-Loeffler-Institute, Germany) were infected with MVA (Institute of Animal Hygiene and Veterinary Public Health, University of Leipzig, Germany) and cultured at $37^{\circ} \mathrm{C}$ in a humid atmosphere under $5.0 \%$ $\mathrm{CO}_{2}$. The virus was cultivated from confluent monolayers with a maximum age of 2 days.

\section{MERS-COV}

Cultivation of MERS-CoV was based on the same overall method as for MVA. The MERS-CoV, HCoV-EMC/2012 (Erasmus Medical Center, Rotterdam, The Netherlands) was used as the test virus. Vero E6 cells (American Type Culture Collection, ATCC) were used for virus cultivation and the suspension test.

\section{Inactivation Assay}

Tests were carried out once in accordance with EN14476:2013/FprA1:2015 at $20 \pm 1{ }^{\circ} \mathrm{C}$ [10]. The test assay comprised $100 \mu \mathrm{L}$ virus suspension, $100 \mu \mathrm{L}$ interfering substance (clean, $0.3 \mathrm{~g} / \mathrm{L}$ bovine serum albumin [BSA] or dirty, $3.0 \mathrm{~g} / \mathrm{L} \mathrm{BSA}+3.0 \mathrm{~mL} / \mathrm{L}$ erythrocytes) and $800 \mu \mathrm{L}$ PVP-I product (undiluted, $1: 10$ or $1: 100$ dilution). A virus control mixture was also assessed using double-distilled water in place of the test product. After the specified contact time $(15,30$ or $60 \mathrm{~s})$, virucidal activity was immediately suppressed by dilution with nine volumes of ice-cold medium (minimal essential medium $+2.0 \%$ fetal calf serum) and serially diluted tenfold. Infectivity was determined by 
means of end point dilution titration in microtiter plates. Aliquots of $100 \mu \mathrm{L}$ from each dilution were added to six $200 \mu \mathrm{L}$ samples of BHK-21 cells. Cultures were examined microscopically for cytopathic effects (CPE) after 8 days of inoculation.

The virus titers were determined using the Spearman-Kärber method $[11,12]$ and expressed as tissue culture infectious dose 50\% $\left(\mathrm{TCID}_{50} / \mathrm{mL}\right)$. The virucidal activity was determined by the difference of the logarithmic titer of the virus control minus the logarithmic titer of the test virus $\left(\Delta \log _{10}\right.$ $\mathrm{TCID}_{50} / \mathrm{mL}$ ). This difference is presented as a reduction factor (RF) including its 95\% confidence interval (CI). A reduction in virus titer of $\geq 4 \log _{10}$ (corresponding to an inactivation of $\geq 99.99 \%$ ) was regarded as evidence of sufficient virucidal activity. The calculation was performed according to EN14476 [10].

\section{Inactivation Assay Using Large Volume Plating (LVP) Method for Verification of Concentration-Contact Time Values with Mers-CoVv}

In accordance with EN14476:2013/FprA1:2015, the inactivation tests were conducted once, at $20 \pm 1{ }^{\circ} \mathrm{C}$ [10]. One part MERS-CoV suspension $(100 \mu \mathrm{L})$ was mixed with $100 \mu \mathrm{L}$ of either $0.3 \mathrm{~g} / \mathrm{L}$ BSA (clean conditions) or $3.0 \mathrm{~g} / \mathrm{L} \mathrm{BSA}+3.0 \mathrm{~mL} /$ $\mathrm{L}$ erythrocytes (dirty conditions) as the interfering substance. The virus-protein mixture was added to 8 parts $(800 \mu \mathrm{L})$ of the undiluted test product. After a contact time of $15 \mathrm{~s}, 20 \mu \mathrm{L}$ of the test mixture was added to $99.98 \mathrm{~mL}$ ice-cold medium. Aliquots $(300 \mu \mathrm{L})$ of the diluted sample were then added to 336 wells containing the indicator cells. The cells were cultivated for 5 days, and then inspected microscopically after 3 and 5 days for virus-induced CPE in cell morphology. Calculations of viral titer (in cases of no virus or low viral count) were as detailed in [8].

\section{RESULTS}

\section{Determination of the PVP-I Kinetics in Clean and Dirty Conditions Using MVA}

The test concentrations and contact periods were chosen to observe the point at which each test preparation produced efficient virus inactivation. To demonstrate virucidal efficacy, disinfectant and antiseptic products are required to produce a $\log _{10}$ reduction in virus titer of at least 4 [10]. The $\log _{10}$ reduction factors produced by the test products under clean and dirty conditions at each time point are shown in Table 2. With each PVP-I formulation, $\log _{10}$ reduction in viral titer $\geq 4$ was demonstrated under clean and dirty conditions after only $15 \mathrm{~s}$ with the undiluted and 1:10 dilutions (except for gargle/mouthwash, which, in dirty conditions, required $30 \mathrm{~s}$ of exposure at the 1:10 dilution).

Under both clean and dirty conditions, the virucidal activity of the PVP-I products varied with the concentration of available iodine as follows: scrub, $0.75 \mathrm{~g} / \mathrm{L}>7.5 \mathrm{~g} / \mathrm{L}>0.075 \mathrm{~g} / \mathrm{L}$; cleanser, $\quad 0.4 \mathrm{~g} / \mathrm{L}>4.0 \mathrm{~g} / \mathrm{L}>0.04 \mathrm{~g} / \mathrm{L}$; gargle/mouthwash, $1.0 \mathrm{~g} / \mathrm{L}>0.1 \mathrm{~g} / \mathrm{L}>0.01 \mathrm{~g} / \mathrm{L}$.

\section{Verification of Concentration-Contact Time Values with MERS-CoV}

The titers of MERS-CoV present in the control samples ranged from 6.00 to $6.50 \log _{10} \mathrm{TCID}_{50} /$ $\mathrm{mL}$ under clean and dirty conditions. MERS-CoV viral titers were reduced between 4.30 and $4.97 \quad \log _{10} \quad \mathrm{TCID}_{50} / \mathrm{mL}$ after $15 \mathrm{~s}$ (Table 2), which corresponds to a reduction in 


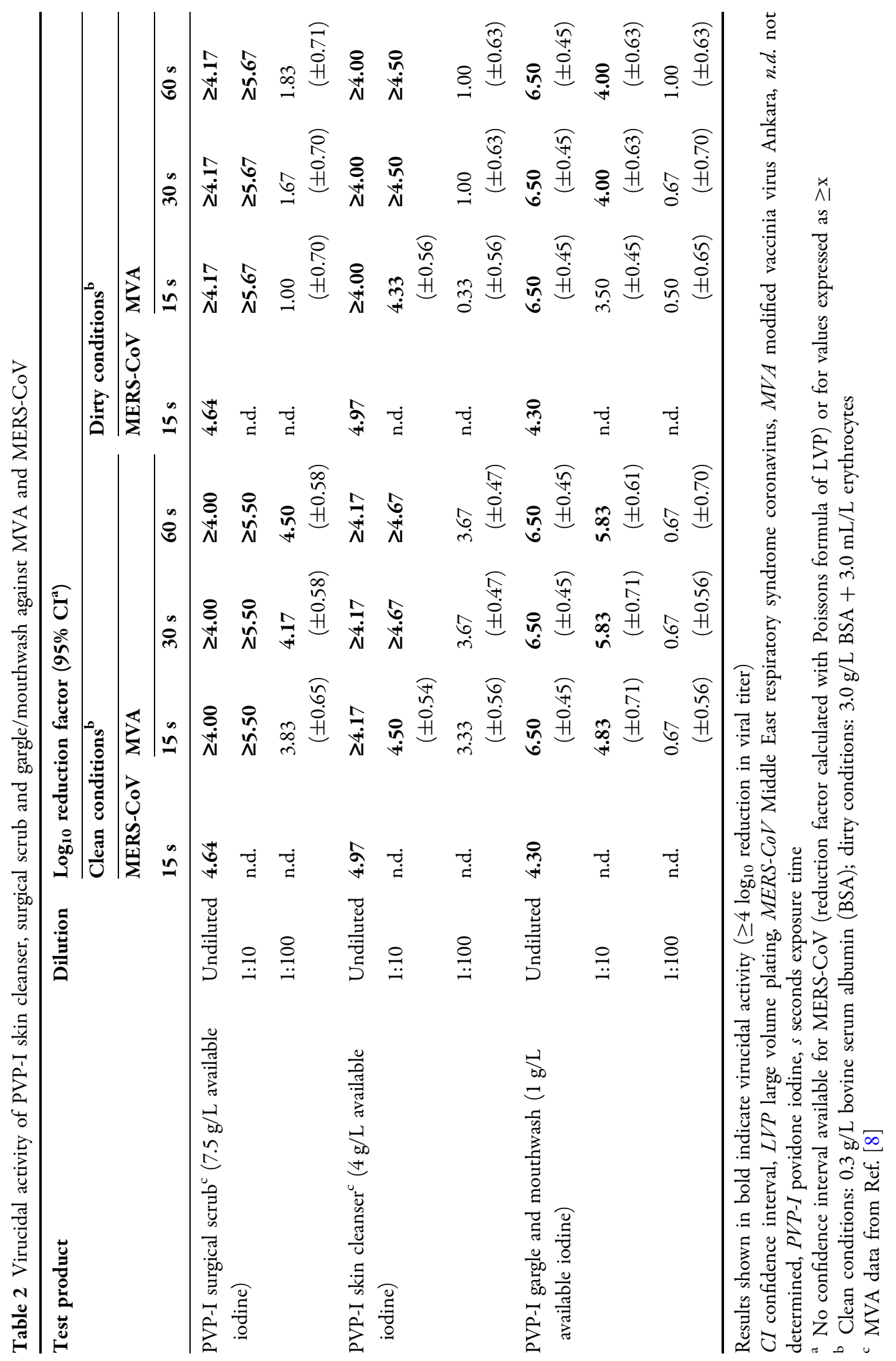


MERS-CoV viral titer of $\geq 99.99 \%$ for all products tested.

\section{DISCUSSION}

As is the case for Ebola, MERS-CoV is an enveloped virus with a high biosafety level, for which there is no vaccination, nor any specific antiviral treatment $[13,14]$. While infection can remain subclinical-indicating that not all cases may be reported-MERS-CoV more typically causes severe respiratory disease. During the first year following the first reported case, two-thirds of patients suffered severe disease [15], and over a third of reported cases to date have been fatal [4].

Containment of spread has proven achievable in most cases; thus far, no sustained human-to-human transmission has occurred anywhere in the world [4]. However, a lack of awareness among health care workers and the general public, coupled with inadequate prevention and control procedures, can result in outbreaks based on nosocomial infection, as recently observed in the Republic of Korea. Based on the current situation, the World Health Organization (WHO) has issued a number of recommendations [4]. Many of these reflect the lack of understanding of how humans become infected from animal or environmental sources, with particular emphasis on precautions relating to exposure to camels. The other focus is on ensuring that health care facilities adopt appropriate measures to decrease the risk of transmission of the virus from an infected patient to other patients, health care workers and visitors.

A practical measure applicable to both of these issues is the implementation of effective hand hygiene practice. Standard hand hygiene includes either washing hands with soap and water or the use of an alcohol-based hand rub [16]. Randomized, controlled trial data are available to support the effectiveness of PVP-I and alcohol hand rubs over plain soap hand wash for hand decontamination, based on post-hygiene colony-forming unit count [17]. In the context of virucidal activity, PVP-I has demonstrated superiority over ethanol-based sanitizers in inactivating murine norovirus on a modified finger pad test [18]. In an evaluation of the effectiveness of nine different hand sanitizers against feline calicivirus (a surrogate for norovirus), antiseptics containing 10\% PVP-I achieved a greater viral reduction rate than any of the alcohol-based sanitizers, non-alcoholic sanitizers or antimicrobial soaps [19]. PVP-I has demonstrated virucidal activity against a range of enveloped and non-enveloped viruses. Perhaps most relevant in the context of the MERS-CoV is the evidence for effective inactivation of the SARS-CoV to below detectable levels within 2 min of exposure [20].

Effective hand hygiene is crucial in minimizing viral transmission from the contaminated hands of an infected individual, either through direct person-to-person contact, or indirectly via contamination of surfaces. However, respiratory viruses are also subject to airborne (particles $\leq 5 \mu \mathrm{m}$ in size) or droplet $(>5 \mu \mathrm{m})$ transmission, in which infected material is released by the infected individual breathing, coughing or sneezing [21]. Gargling represents an effective personal hygiene measure against airborne/droplet transmission, as it can reduce the microbe count at the pharynx [22]. Together with hand washing and mask use, it has been proposed that gargling is one of the three major personal hygiene protection measures against common airborne and droplet-transmitted infections [22]. Specialists advise that the criteria for 
selecting mouthwashes should include effectiveness of the antiseptic agent in killing pathogens [22]. Given the strong in vitro virucidal activity of PVP-I demonstrated in this and other studies, gargling/flushing with PVP-I may be an effective measure to disrupt the transmission of respiratory viruses, especially via airborne/droplet transmission or after uptake via the mouth (such as when touching the mouth or food with contaminated hands).

The data reported here indicate rapid virucidal activity of three formulations of PVP-I against both MVA and MERS-CoV. The 15-s exposure time was assessed to study the virucidal kinetics of PVP-I against MVA over time (the minimum contact time for hygienic hand rub and hand wash defined in EN14476:2013 is $30 \mathrm{~s} \mathrm{[10]),} \mathrm{and} \mathrm{yet} \mathrm{proved}$ sufficient for all three formulations to be effective, against both MVA and MERS-CoV.

MERS-CoV is a harmful enveloped virus and requires high biosafety levels for any investigation. It is not recommended that disinfectants are tested using highly contagious and harmful viruses; thus, model viruses are used. The CEN/TC 216/WG1 committee, which establishes standardized European testing methods and requirements for the antimicrobial efficacy of chemical disinfectants and antiseptics, recently implemented the enveloped MVA as the model virus for the claim 'virucidal active against enveloped viruses for hygienic hand rub and hand wash'. MVA was chosen on the basis of its low biosafety level, its known environmental stability and its practicability for laboratory use [23-25]. On the basis of these practical safety concerns, our study was conducted primarily using MVA with confirmation only in MERS-CoV.

Usually, only low titers of MERS-CoV can be harvested in cell culture, resulting in a range of
5.00-6.50 $\log _{10} \mathrm{TCID}_{50} / \mathrm{mL}$. To demonstrate at least a $4 \log _{10}$ reduction in virus titer, it is necessary for test mixtures containing low virus titers to undergo detoxification by molecular sieving, or to use a more sensitive assay such as LVP [26]. In LVP, a high volume of the lowest apparently non-cytotoxic dilution of the inactivation assay test mixture is added to the detector cell line and the cultures are monitored for virus-specific effects. Using this method, larger reductions in virus titer can be shown even at lower viral loads and contact times as short as $15 \mathrm{~s}$ can be tested, minimizing the impact of any after effects. LVP offers sufficient sensitivity for reductions in virus titer to be detected even using test products that are highly cytotoxic in cell culture [27].

It should be considered that while the results of this in vitro analysis are a suitable basis for predictions about the virucidal efficacy of PVP-I, they do not provide direct information about the effectiveness of the products in practice. However, taken together with: (1) the emphasis placed by WHO on ensuring suitable levels of hand hygiene; (2) recommendations for gargling with antiseptic mouthwash for the control of common airborne and droplet-transmitted infections [22]; (3) the fact that PVP-I is a product already in use and available within the most affected regions of the world, these data provide strong rationale for the use of PVP-I products for the prevention of infection by MERS-CoV. Improved awareness is needed in the health care setting to ensure effective containment of the spread of this often fatal virus.

\section{CONCLUSION}

The outbreak of MERS-CoV in the Republic of Korea is testament to the ongoing risk of healthcare-associated transmission, and 
reinforces the need for timely diagnosis and implementation of prevention and control measures. The three PVP-I products tested in this study demonstrated virucidal activity against MVA and MERS-CoV at room temperature, within only $15 \mathrm{~s}$ of exposure. This was observed under both clean and dirty conditions. These data are consistent with those from other studies demonstrating the excellent virucidal activity of PVP-I against enveloped viruses.

The data reported here indicate that PVP-I-based hand wash products for potentially contaminated skin, together with PVP-I gargle/mouthwash for reduction of viral load in the oral cavity and the oropharynx, may help to support hygiene measures during outbreaks of respiratory viruses.

\section{ACKNOWLEDGMENTS}

We thank Katharina Kowalski, Institute for Virology, Philipps University of Marburg, Germany, who carried out the virucidal tests with MERS-CoV and Becky Fox-Spencer who provided medical writing services on behalf of Mundipharma Research GmbH \& Co. KG, Germany.

This research, article processing charges and medical writing assistance was funded by Mundipharma Research GmbH \& Co. KG, Germany.

MEg was responsible for the study design and performed the statistical analysis, provided analysis and interpretation of data, and carried out the virucidal tests with MVA. ME carried out the virucidal tests with MERS-CoV and provided analysis and interpretation of data. JZ participated in the original planning and design of the study and contributed to the interpretation of results as well as to the manuscript.

All named authors meet the International Committee of Medical Journal Editors (ICMJE) criteria for authorship for this manuscript, take responsibility for the integrity of the work as a whole, and have given final approval to the version to be published.

Disclosures. JZ is an employee of Mundipharma Research GmbH \& Co. KG and has no other financial or non-financial competing interests. MEg and ME have nothing to disclose.

Compliance with ethics guidelines. This article does not contain any new studies with human or animal subjects performed by any of the authors.

Open Access. This article is distributed under the terms of the Creative Commons Attribution-NonCommercial 4.0 International License (http://creativecommons.org/licenses/ by-nc/4.0/), which permits any noncommercial use, distribution, and reproduction in any medium, provided you give appropriate credit to the original author(s) and the source, provide a link to the Creative Commons license, and indicate if changes were made.

\section{REFERENCES}

1. Berry M, Gamieldien J, Fielding BC. Identification of new respiratory viruses in the new millennium. Viruses. 2015;7(3):996-1019.

2. Centers for Disease Control and Prevention. Frequently Asked Questions about SARS. http:// www.cdc.gov/sars/about/faq.html. Accessed July 2015.

3. Zaki AM, van Boheemen $\mathrm{S}$, Bestebroer TM, Osterhaus AD, Fouchier RA. Isolation of a novel 
coronavirus from a man with pneumonia in Saudi Arabia. N Engl J Med. 2012;367(19):1814-20.

4. World Health Organization (WHO). Middle East respiratory syndrome coronavirus (MERS-CoV) Summary of Current Situation, Literature Update and Risk Assessment. 2015. http://apps.who.int/ iris/bitstream/10665/179184/2/WHO_MERS_RA_15. 1_eng.pdf?ua=1. Accessed July 2015.

5. World Health Organization (WHO). Emergencies preparedness, response. Summary and risk assessment of current situation in Republic of Korea and China. http://www.who.int/csr/disease/ coronavirus_infections/risk-assessment-19june2015 /en/. Accessed July 2015.

6. World Health Organization (WHO). WHO Statement on the 9th Meeting of the IHR Emergency Committee Regarding MERS-CoV. http://www.who.int/mediacentre/news/statements/ 2015/ihr-ec-mers/en/. Accessed July 2015.

7. World Health Organization (WHO). Frequently Asked Questions on Middle East Respiratory Syndrome cornonavirus (MERS-CoV). http://www. who.int/csr/disease/coronavirus_infections/faq/en/ . Accessed July 2015.

8. Eggers M, Eickmann M, Kowalski K, Zorn J, Reimer $\mathrm{K}$. Povidone-iodine hand wash and hand rub products demonstrated excellent in vitro virucidal efficacy against Ebola virus and Modified vaccinia virus Ankara, the new European test virus for enveloped viruses. BMC Infect Dis. 2015;15:375. doi:10.1186/s12879-015-1111-9.

9. Al-Saeed MY, Babay N. The use of povidone-iodine and hydrogen peroxide mixture as an adjunct to non-surgical treatment of slight to moderate chronic periodontitis. Saudi Dent J. 2009;21(3): 127-33.

10. EN14476:2013/FprA1:2015: Chemical disinfectants and antiseptics. Quantitative suspension test for the evaluation of virucidal activity in the medical area. Test method and requirements (Phase 2/Step 1). 2015.

11. Spearman C. The method of 'right and wrong cases' ('constant stimuli') without Gauss's formulae. Br J Psychol. 1908;2:227-42.

12. Kärber G. Beitrag zur Kollektiven Behandlung Pharmakologischer Reihenversuche [article in German]. Arch Exp Path Pharma. 1931;162:480-7.

13. World Health Organization (WHO). Essential Medicines and Health Products: Ebola vaccines, therapies, and diagnostics. http://www.who.int/ medicines/emp_ebola_q_as/en/. Accessed July 2015 .
14. Centers for Disease Control and Prevention. Middle East Respiratory Syndrome (MERS): Prevention and Treatment. http://www.cdc.gov/coronavirus/mers/ about/prevention.html. Accessed July 2015.

15. WHO MERS-CoV Research Group. State of knowledge and data gaps of Middle East respiratory syndrome coronavirus (MERS-CoV) in humans. PLoS Curr. 2013;5. doi:10.1371/currents. outbreaks.0bf719e352e7478f8ad85fa30127ddb8.

16. World Health Organization (WHO). Infection prevention and control during health care for probable or confirmed cases of Middle East respiratory syndrome coronavirus (MERS-CoV) infection. Interim guidance; updated 4 June 2015. http://www.who.int/csr/disease/coronavirus infections/ipc-mers-cov/en/. Accessed July 2015.

17. Sharma VS, Dutta S, Taneja N, Narang A. Comparing hand hygiene measures in a neonatal ICU: a randomized crossover trial. Indian Pediatr. 2013;50(10):917-21.

18. Steinmann J, Paulmann D, Becker B, Bischoff B, Steinmann E, Steinmann J. Comparison of virucidal activity of alcohol-based hand sanitizers versus antimicrobial hand soaps in vitro and in vivo. J Hosp Infect. 2012;82(4):277-80.

19. Lages SL, Ramakrishnan MA, Goyal SM. In-vivo efficacy of hand sanitisers against feline calicivirus: a surrogate for norovirus. J Hosp Infect. 2008;68(2):159-63.

20. Kariwa H, Fujii N, Takashima I. Inactivation of SARS coronavirus by means of povidone-iodine, physical conditions and chemical reagents. Dermatology. 2006;212(Suppl 1):119-23.

21. Gralton J, Tovey ER, McLaws ML, Rawlinson WD. Respiratory virus RNA is detectable in airborne and droplet particles. J Med Virol. 2013;85(12):2151-9.

22. Yung D, Tang M. Press release: 10 years after SARS-improper hand washing in the majority of HK people coupled with a $25 \%$ drop in cold \& flu sick leave for reducing risk of spreading of germs doctor urges to regain strict personal hygiene habits. 2013. http://hkupop.hku.hk/english/ report/postSARS/content/resources/pr.pdf. Accessed July 2015.

23. Stittelaar KJ, Kuiken T, de Swart RL, van Amerongen G, Vos HW, Niesters HG, et al. Safety of modified vaccinia virus Ankara (MVA) in immune-suppressed macaques. Vaccine. 2001;19:3700-9.

24. Richmond JY, McKinney RW, editors. Biosafety in microbiological and biomedical laboratories. 4th ed. Washington: CDC-NIH; 1999. 
25. Sparkes JD, Fenje P. The effect of residual moisture in lyophilized smallpox vaccine on its stability at different temperatures. Bull World Health Organ. 1972;46:729-34.

26. Rabenau HF, Schwebke I, Blümel J, Eggers M, Glebe D, Rapp I, et al. Leitlinie der Deutschen Vereinigung zur Bekämpfung der Viruskrankheiten (DVV) e.V. und des Robert Koch-Instituts (RKI) zur Prüfung von chemischen Desinfektionsmitteln auf Wirksamkeit gegen Viren in der Humanmedizin [article in German].

27. Ruppach $H$. $\log _{10}$ reduction factors in viral clearance studies. Bioprocess J. 2014;12(4):24-30. 